\title{
Possible cause of extremely bright aurora witnessed in East Asia on 17 September 1770
}

\section{$\operatorname{AUTHOR}(\mathrm{S}):$}

Ebihara, Yusuke; Hayakawa, Hisashi; Iwahashi, Kiyomi; Tamazawa, Harufumi; Kawamura, Akito Davis; Isobe, Hiroaki

\section{CITATION:}

Ebihara, Yusuke ... [et al]. Possible cause of extremely bright aurora witnessed in East Asia on 17 September 1770. Space Weather 2017, 15(10): 1373-1382

\section{ISSUE DATE:}

2017-10

URL:

http://hdl.handle.net/2433/237235

\section{RIGHT:}

An edited version of this paper was published by AGU. Copyright 2017 American Geophysical Union 


\section{RESEARCH ARTICLE}

10.1002/2017SW001693

\section{Key Points:}

- Extremely bright red aurora, probably related to type $A$ aurora, was witnessed in East Asia (magnetic latitudes of $\sim 25^{\circ}$ ) in September 1770

- Unusually high-intensity low-energy electrons (HILEEs) probably precipitated at magnetic latitude as low as $\sim 32^{\circ}$

- Earthward displacement of low-energy electrons to $L \sim 1.39$ or local heating/acceleration processes might result in HILEEs

Supporting Information:

- Supporting Information S1

Correspondence to:

Y. Ebihara,

ebihara@rish.kyoto-u.ac.jp

Citation:

Ebihara, Y., Hayakawa, H., Iwahashi, K., Tamazawa, H., Kawamura, A. D., \& Isobe, H. (2017). Possible cause of extremely bright aurora witnessed in East Asia on 17 September 1770. Space Weather, 15, 1373-1382. https://doi.org/ 10.1002/2017SW001693

Received 20 JUL 2017

Accepted 25 SEP 2017

Accepted article online 10 OCT 2017

Published online 25 OCT 2017

(2017. American Geophysical Union. All Rights Reserved.

\section{Possible Cause of Extremely Bright Aurora Witnessed in East Asia on 17 September 1770}

\author{
Yusuke Ebihara $^{1,2}$ (D), Hisashi Hayakawa ${ }^{3,4}$ (D), Kiyomi Iwahashi' ${ }^{5}$, Harufumi Tamazawa ${ }^{6}$, \\ Akito Davis Kawamura ${ }^{6}$, and Hiroaki Isobe ${ }^{2,7}$ \\ ${ }^{1}$ Research Institute for Sustainable Humanosphere, Kyoto University, Kyoto, Japan, ${ }^{2}$ Unit of Synergetic Studies for Space, \\ Kyoto University, Kyoto, Japan, ${ }^{3}$ Graduate School of Letters, Osaka University, Toyonaka, Japan, ${ }^{4} J S P S$ Research Fellow, \\ Tokyo, Japan, ${ }^{5}$ National Institute of Japanese Literature, Tachikawa, Japan, ${ }^{6}$ Kwasan Observatory, Kyoto University, Kyoto, \\ Japan, ${ }^{7}$ Graduate School of Advanced Integrated Studies in Human Survivability, Kyoto University, Kyoto, Japan
}

Abstract Extremely bright aurora was witnessed in East Asia on 17 September 1770, according to historical documents. The aurora was described as "as bright as a night with full moon" at magnetic latitude of $25^{\circ}$. The aurora was dominated by red color extending from near the horizon up beyond the polar star (corresponding to elevation angle of $\sim 35^{\circ}$ ). We performed a two-stream electron transport code to calculate the volume emission rates at $557.7 \mathrm{~nm}(\mathrm{Ol})$ and $630.0 \mathrm{~nm}(\mathrm{Ol})$. Two types of distribution of precipitating electrons were assumed. The first one is based on the unusually intense electron flux measured by the DMSP satellite in the March 1989 storm. The distribution consists of hot (peaking at $3 \mathrm{keV}$ ) and cold (peaking at $71 \mathrm{eV}$ ) components. The second one is the same as the first one, but the hot component is removed. We call this high-intensity low-energy electrons (HILEEs). The first spectrum results in an auroral display with a bright, lower green border. The second one results in red-dominated aurora extending up to the elevation angle of $35^{\circ}$ when the equatorward boundary of the electron precipitation is located at $32^{\circ}$ invariant latitude. The poleward boundary of the precipitation would be $42^{\circ}$ invariant latitude or greater to explain the auroral display extending from near the horizon. The origin of the HILEEs is probably the plasma sheet or the plasmasphere that is transported earthward to $L \sim 1.39$ due to enhanced magnetospheric convection. Local heating or acceleration is also plausible.

Plain Language Summary Extremely bright aurora was witnessed at magnetic latitudes of $25^{\circ}$ in Japan and China in September 1770. The aurora was described as "as bright as a night with full moon" and "red vapor appeared northward and shone so bright that one can identify others' face." After calculation of auroral emission, we found that the extremely bright aurora is probably realistic and that a combination of the two factors is needed to explain it. One is unusual precipitation of electrons with extremely high intensity and extremely low temperature. The other is substantial displacement of the cold electrons toward the Earth.

\section{Introduction}

Aurora is caused by particles precipitating into the upper atmosphere. At low latitudes, the aurora is known to appear with magnetic storms (e.g., Gonzalez et al., 1994; Lakhina et al., 2013; Noxon \& Evans, 1976; Rohrbaugh et al., 1983; Shiokawa et al., 1997; Shiokawa, Ogawa, \& Kamide, 2005; Tinsley et al., 1986) because the auroral oval moves equatorward (e.g., Yokoyama, Kamide, \& Miyaoka, 1998). A major characteristics of the lowlatitude aurora is the dominance of the "red line" of auroral emission at $630.0 \mathrm{~nm}$ (OI) (Noxon \& Evans, 1976; Rohrbaugh et al., 1983; Tinsley et al., 1984, 1986). At McDonald Observatory (39.8 magnetic latitude, MLAT), the emission at $630.0 \mathrm{~nm}$ with an intensity of $20 \mathrm{kR}$ was observed on 13 April 1981. The intensity ratio of $630.0 \mathrm{~nm}$ to that of $557.0 \mathrm{~nm}, I(630.0) / /(557.7)$, was 20, implying substantial precipitation of low-energy electrons. The aurora with its upper part being dominated by the red color is called a type $A$ aurora (Chamberlain, 1961). A direct measurement of precipitating electrons in the type A aurora was conducted in Fort Churchill (68.8 MLAT) on 17 August 1970 (McEwen \& Sivjee, 1972). The I(630.0)//(557.7) ratio was 4, and low-energy electrons ( $<1 \mathrm{keV}$ ) were indeed enhanced. Shiokawa et al. (1997) observed precipitation of electrons with magnitude being intensified in a broad energy range, at least, from $30 \mathrm{eV}$ to $\sim 30 \mathrm{keV}$ when the aurora dominated by the red color appeared at Rikubetsu $\left(34.7^{\circ} \mathrm{MLAT}\right)$ in Japan. The spectral characteristics of precipitating electrons is called broadband electrons. By using a two-stream electron transport code, Shiokawa et al. (1997) suggested that the broadband electrons are responsible to the reddish aurora 


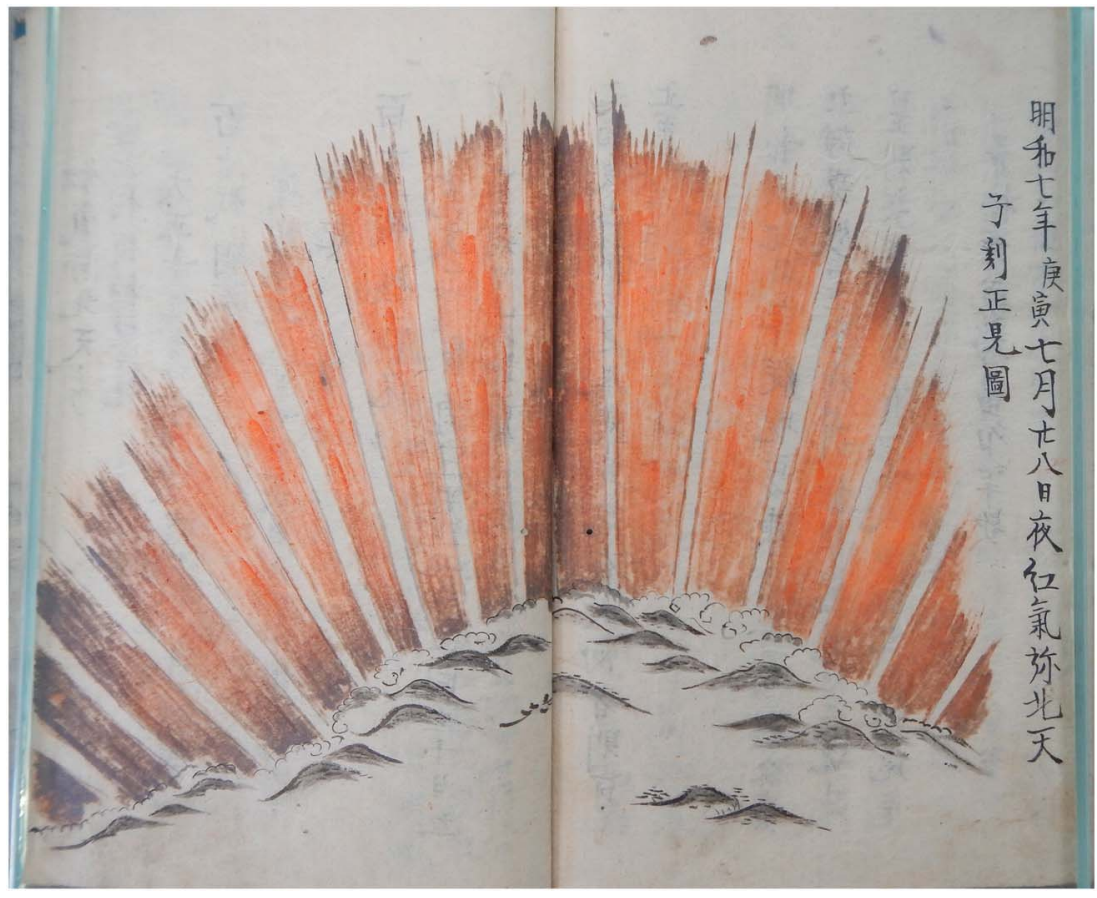

Figure 1. Drawing of "red vapor" witnessed on 17 September 1770 at Kyoto, Japan (Seikai-M, ff. 25b-26a; see Text S1 for detailed information, courtesy of Matsusaka Municipal Library for Local History).

observed at Rikubetsu and that the green lower border was hidden below the horizon. Shiokawa et al. (2005) summarized auroral observations conducted at Rikubetsu, Moshiri (34.9 MLAT), and Shigaraki (25.4 ${ }^{\circ}$ MLAT) in Japan from 1989 to 2004. The brightest aurora was observed at Moshiri on 21 October 1989 with the brightness $>8.8 \mathrm{kR}$ (Miyaoka et al., 1990) associated with a magnetic storm with minimum Dst of $-268 \mathrm{nT}$. At Shigaraki, aurora was observed on 31 March 2001 and 30 October 2003 associated with magnetic storms with minimum Dst of $-387 \mathrm{nT}$ and $-363 \mathrm{nT}$, respectively. The intensities of the aurora observed on 31 March 2001 were $>2.1 \mathrm{kR}$ at $630.0 \mathrm{~nm}$ and $0.2 \mathrm{kR}$ at $557.7 \mathrm{~nm}$. Shiokawa et al. (2003) suggested that the aurora observed on 31 March 2001 was probably associated with stable auroral red (SAR) arcs. The SAR arcs are monochromatic spectral character with almost entire red emission (the ratio of emission at $630.0 \mathrm{~nm}$ to that at $557.7 \mathrm{~nm}$ is 80:1) (Rees, 1961). As for the aurora observed on 30 October 2003, the intensities were $0.1 \mathrm{kR}$ at $630.0 \mathrm{~nm}$ and $0.4 \mathrm{kR}$ at $557.7 \mathrm{~nm}$.

The low-latitude aurora that can be clearly witnessed by naked eyes is infrequent. On 11 February 1958, the bright aurora dominated by red color was seen in the north part of Japan (Hikosaka, 1958). The intensity of the red doublet at $630.0 \mathrm{~nm}$ and $636.4 \mathrm{~nm}$ was observed to reach $\sim 200 \mathrm{kR}$ at Memambetsu (34.0 MLAT) at 0930 UT (Saito, Kiyama, \& Takahasi, 1994). Hikosaka (1958) stated "It was first noticed at about 0900 U.T. as a red glow on the northern horizon and became a large HA by about 1000 U.T., when, overlapping the arc, bright orange-white columns of light like the beams of searchlight appeared. ... It was as bright as a moonlit cumulus (brightness grade 3). The elevation of the arc measured at 1045 U.T. by the members of the meteorological station of Abashiri $\left(44.0^{\circ} \mathrm{N}, 144.3^{\circ} \mathrm{E}\right)$ was $13.2^{\circ}$ at the lower border and $47^{\circ}$ at the summit." We note that the magnetic latitude of Abashiri is $34.1^{\circ}$. Bright aurora was also witnessed at low latitudes in August-September 1859, which is referred to as Carrington event (Kimball, 1960; Tsurutani et al., 2003; Cliver \& Svalgaard, 2004; Cliver \& Dietrich, 2013; Hayakawa, Iwahashi, et al., 2016; Lakhina \& Tsurutani, 2016). The aurora was described as "enable a person to read coarse print" in Kanosha $\left(40^{\circ} 51^{\prime} \mathrm{N}, 95^{\circ} 44^{\prime} \mathrm{W}, 50.4^{\circ} \mathrm{MLAT}\right)$ in 28 August 1859 (Loomis, 1860), "fine newspaper print could be read by it" at Cahawba $\left(32^{\circ} 19^{\prime} \mathrm{N}, 87^{\circ} 16^{\prime} \mathrm{W}, 42.8 \mathrm{MLAT}\right)$ (Loomis, 1860) during the night 1-2 September 1859, and suspected as "conflagration" by four of four contemporary Japanese chroniclers and diarists (Hayakawa, Iwahashi, et al., 2016).

Another extremely bright red aurora was witnessed in East Asia including Japan in September 1770 (Hayakawa, Iwahashi, et al., 2016; Nakazawa, Okada, \& Shiokawa, 2004; Willis, Stephenson, \& Singh, 1996). A chronicler in Shingu, Japan $\left(33^{\circ} 44^{\prime} \mathrm{N}, 135^{\circ} 59^{\prime} \mathrm{E}, 23.7^{\circ} \mathrm{MLAT}\right)$, noted "At night, from Mutsudoki (17:00-19:00) until midnight, it 
(a) 14 March 1989 (DMSP F08)
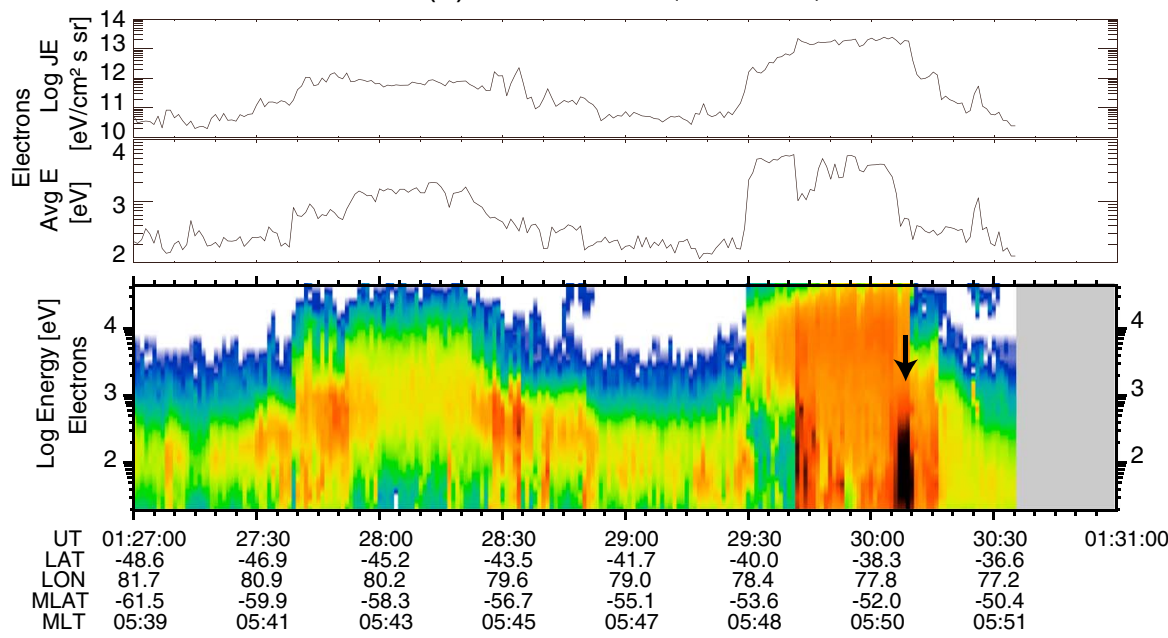

(b) 31 October 2003 (DMSP F13)
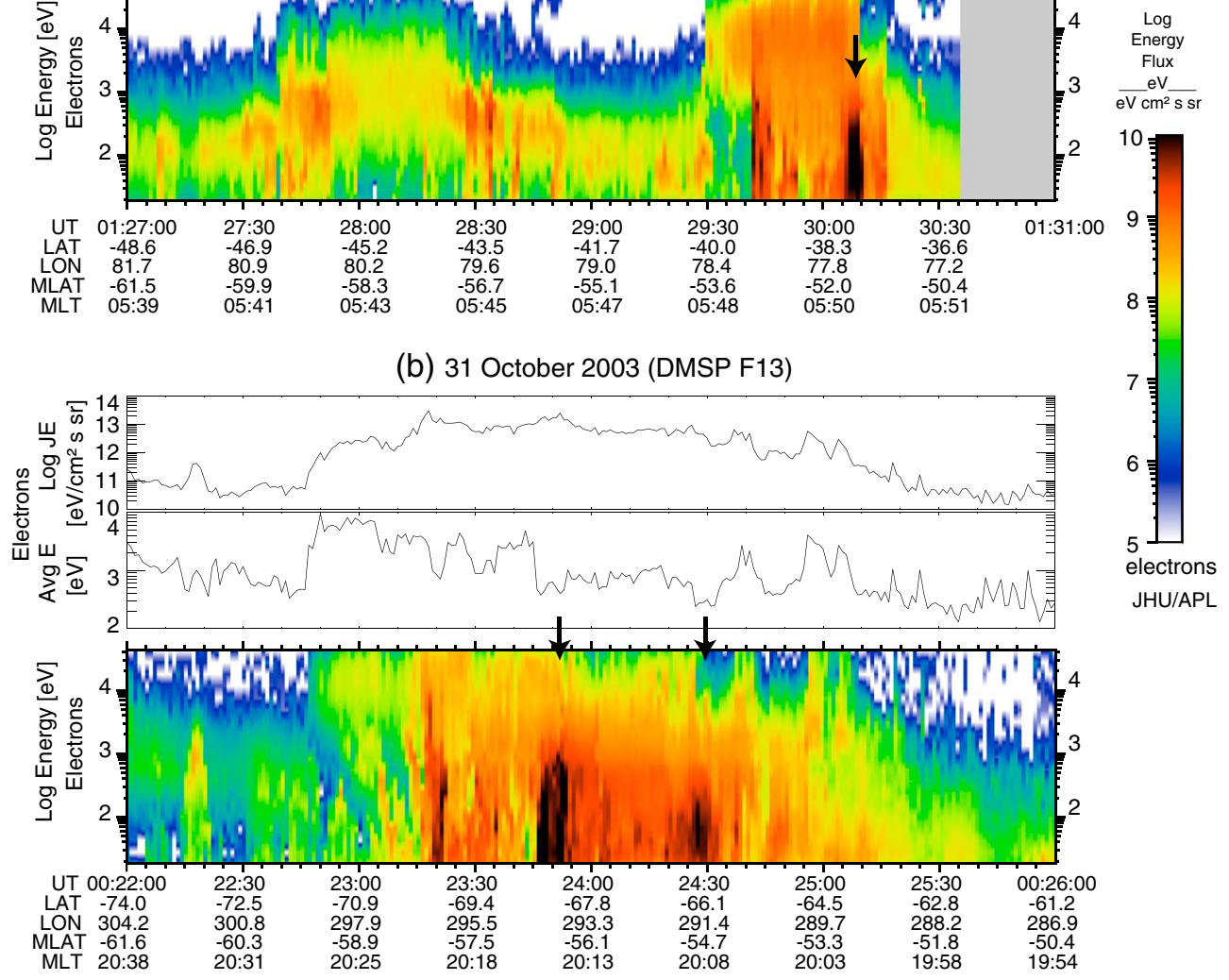

Figure 2. Integrated flux (JE) and averaged energy (Ave E) of precipitating electrons together with spectrograms of precipitating electrons observed by (a) DMSP F8 on 14 March 1989 and (b) DMSP F13 on 31 October 2003.

was as red as a conflagration in the north. This is the first time in 90 years since red vapor had also appeared in the north on 1770/09/17." (Hayakawa, Iwahashi, et al., 2016). Figure 1 shows an example of the drawing that probably

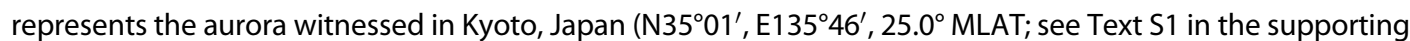
information for detailed information) on 17 September 1770 . Bright emission with white stripes extending from near the horizon to high-elevation angles is clearly drawn. The bright red emission seems to be dominant and is probably related to type A aurora (Chamberlain, 1961). It seems that the aurora presented in Figure 1 is reddominated with no green lower border, which may belong to type $d$ aurora (Vallance Jones, 1971). The type $\mathrm{d}$ aurora is a subset of the type A red aurora in which the red form with green lower border (Rassoul et al., 1993). The witnessed emission is most likely distinguished from stable auroral red (SAR) arcs because the white lines that probably represent auroral rays are drawn in the drawing.

Regarding brightness, the aurora was described as "as bright as a night with full moon" in Nagoya, Japan

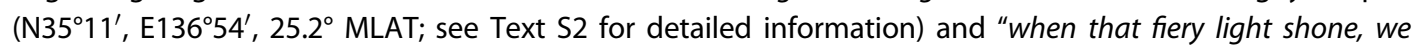
were able to read fine letters and lines of palm clearly as well" in Toyoda, Japan (N34 $52^{\prime}$, E137 $47^{\circ}, 25.0^{\circ}$ MLAT; see Text S3 for detailed information). The following description is also found as "one was able to

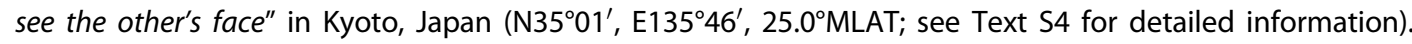
The description in Toyoda, people could read text, is similar to that recorded in Kanosha and Cahawba in August 1859 (Loomis, 1860). However, the magnetic latitude is quite different. In August 1859, the 

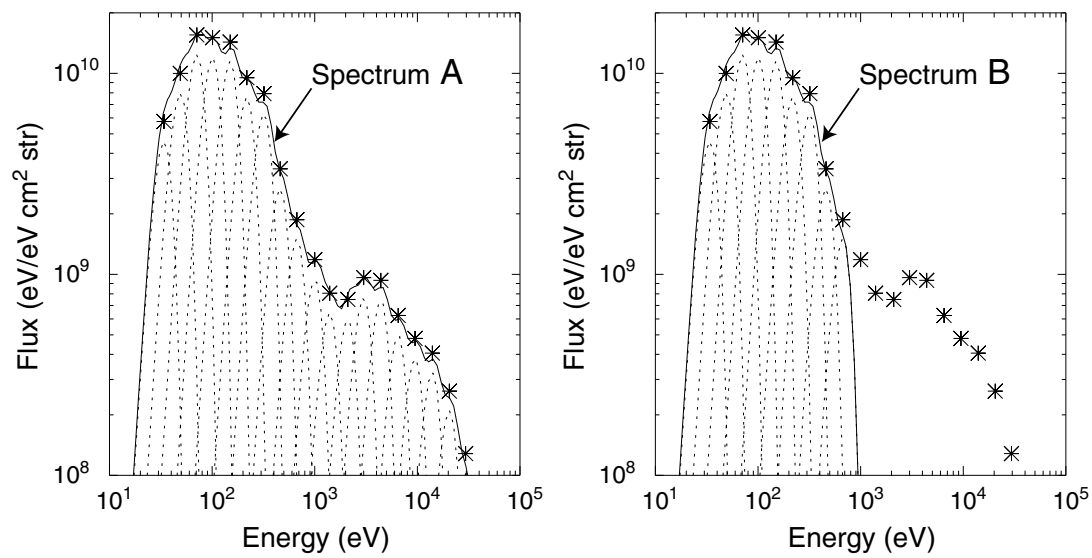

Figure 3. The star symbol indicates precipitating electron flux observed by the DMSP F8 satellite at 0130:08 UT on 14 March 1989. The dotted line indicates the Gaussian distribution with characteristic energy $E_{0}$ corresponding to the center energy of the channel of the particle detector and width of $0.25 E_{0}$. The solid line indicates the sum of the 19 Gaussian distributions. Spectrum A consists of the whole Gaussian distributions, whereas Spectrum B consists of the first nine Gaussian distributions with energy less than $1 \mathrm{keV}$.

descriptions were recorded at $50.4^{\circ}$ and $42.8^{\circ}$ MLAT. In September 1770, the description was recorded at 25. $0^{\circ}$ MLAT. Regarding vertical extension, the aurora was described as "a fiery light like vermilion sand in the north with something with golden color rising up inside beyond the polar star" in Toyoda, Japan (see Text S3). In China, the description "red during night, as bright as the daytime" was recorded in Zhèngyáng (N32 $36^{\circ}$, $\mathrm{E} 114^{\circ} 23^{\prime}, 22.5^{\circ} \mathrm{MLAT}$; see Text S5 for detailed information) on 17 September 1770 . The MLAT was calculated by using the GUFM1 empirical geomagnetic field model (Jackson, Jonkers, \& Walker, 2000) for 1859 and 1770. As for 1900 and onward, we used the IGRF-12 model. The MLAT is defined as $90^{\circ}-\theta$, where $\theta$ is the angle from the dipole axis defined by the GUFM1 model.
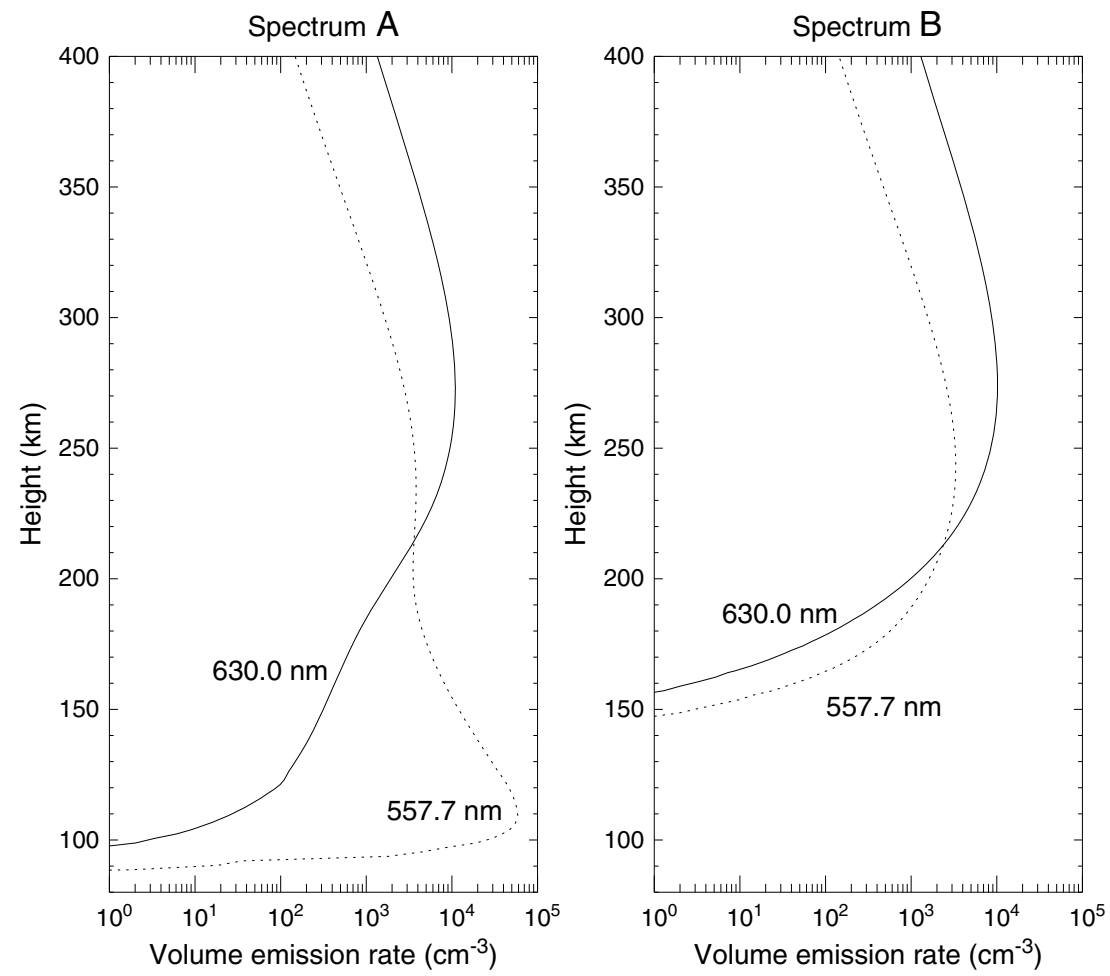

Figure 4. Volume emission rate at $557.7 \mathrm{~nm}(\mathrm{OI})$ and $630.0 \mathrm{~nm}(\mathrm{OI})$ as a function of height for precipitating electrons with (left) Spectrum A and (right) Spectrum B. 

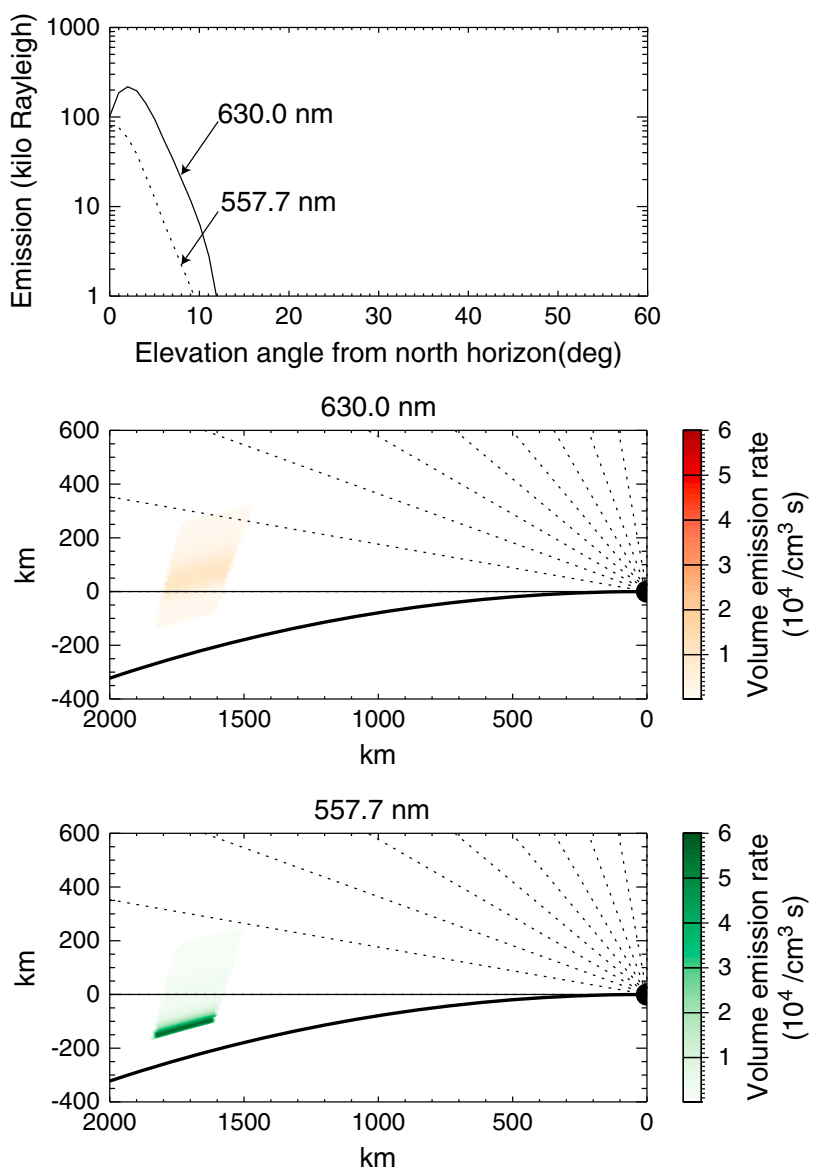

Figure 5. Calculation result for Spectrum A. Electron precipitation is restricted in the region between $40^{\circ}$ and $42^{\circ}$ invariant latitudes. (top) Column emission rates (line-of-sight integral of volume-emission rates) at $630.0 \mathrm{~nm}$ and $557.7 \mathrm{~nm}$ from the point of an observer as a function of elevation angle from north horizon, (middle) the volume emission rate at $630.0 \mathrm{~nm}$ "red aurora," and (bottom) the volume emission rate at $557.7 \mathrm{~nm}$ "green aurora." The filled circle represents the location of the observer at $25^{\circ} \mathrm{MLAT}$, and the solid curve indicates the surface of the Earth. The magnetic north is to the left.
The brightness described in the premodern documents cannot be converted to a numerical quantity. A clue is found in the historical document "as bright as a night with full moon" in Nagoya (see Text S2). This may correspond to Class IV of International Brightness Coefficient (IBC), in which a total illumination at the ground is equivalent to full moonlight (Chamberlain, 1961). IBC Class IV is suggested to correspond to the brightness of 1000 kilo Rayleigh (kR) for the "green aurora" at $557.7 \mathrm{~nm}$ (Hunten et al., 1956). Recalling that the maximum brightness of the aurora recorded in Japan between 1989 and 2004 is >8.8 kR (Shiokawa et al., 2005; Miyaoka et al., 1990), we think that the aurora witnessed in Japan on 17 September 1770 is probably much brighter than observed in Japan between 1989 and 2004. Thus, the September 1770 aurora is thought to be unusual in terms of brightness. The purpose of this paper is to investigate the possible cause of the extremely bright red aurora that might belong to IBC Class IV.

\section{Precipitating Electron Models}

We have no information about the electrons precipitating into the upper atmosphere for 1770 . We speculated spectra of precipitating electrons on the basis of data from the DMSP satellites. Figure 2 summarizes spectrograms of precipitating electrons observed by the DMSP satellites during large magnetic storms. In Figure 2a, the spectrogram taken by the DMSP F8 satellite on 14 March 1989 is shown, which was observed in a large magnetic storm with minimum Dst of $-589 \mathrm{nT}$. Intense precipitation of electrons is found to occur in the region from $-54^{\circ}$ to $-51^{\circ}$. The electron flux reached $\sim 2 \times 10^{13} \mathrm{eV} / \mathrm{cm}^{2} \mathrm{~s}$ str. A remarkably intense precipitation is found at energy less than $\sim 1 \mathrm{keV}$ around 01:30:08 UT at $-51.5^{\circ}$ MLAT as indicated by the arrow. Similar intense precipitation of low-energy electrons were also found on 31 October 2003 as shown in Figure 2b. The minimum Dst was -383 nT. DMSP F13 observed similar spectra around $-54.0^{\circ}$ MLAT on 15 July 2000 and $-54.8^{\circ}$ MLAT on 29 May 2003.

\section{Model Calculation}

Two-stream electron transport code was used to calculate the volume emission rates of the "green aurora" at $557.7 \mathrm{~nm}$ and the "red aurora" at $630.0 \mathrm{~nm}$ (Ono, 1993; Ono \& Hirasawa, 1992). The precipitating electrons were assumed to consist of multiple Gaussian-type energy distributions. Each Gaussian-type distribution has a form $j_{0} \exp \left(-\left(E-E_{0}\right)^{2} / W^{2}\right)$, where $j_{0}$ is the maximum flux, $E$ is the kinetic energy of the electron, $E_{0}$ is the characteristic energy, and $W$ is the width being $0.25 E_{0}$. Figure 3 shows the modeled spectra of precipitating electrons. Spectrum A consists of 19 Gaussian-type distributions to reproduce the electron flux observed by the DMSP F8 satellite at 01:30:08 UT on 14 March 1989. For each Gaussian-type distribution, the characteristic energy $E_{0}$ corresponds to the center energy of the energy channel of the particle detector, and $j_{0}$ corresponds to the differential flux multiplied by 0.8 . It is obviously seen that Spectrum A consists of two components: cold one having peak energy at $71 \mathrm{eV}$ and hot one having peak energy at $3 \mathrm{keV}$. The hot component is probably associated with the plasma sheet origin. The cold one seems to be unusually enhanced, and independent of the hot component, according to the spectrogram shown in Figure 2a. In order to evaluate the contribution from the cold one, we employed Spectrum B that consists of the first nine Gaussian-type distributions with energy less than $1 \mathrm{keV}$. The flux of Spectrum A is $2.0 \times 10^{13} \mathrm{eV} /$ $\mathrm{cm}^{2} \mathrm{~s}$ str, and the flux of Spectrum B is $5.7 \times 10^{12} \mathrm{eV} / \mathrm{cm}^{2} \mathrm{~s}$ str. These electrons are placed at $500 \mathrm{~km}$ altitude at limited invariant latitudes. The reaction rate for the photo emissions $\mathrm{O}\left({ }^{1} \mathrm{~S}\right) \rightarrow \mathrm{O}\left({ }^{1} \mathrm{D}\right)+h v(557.7 \mathrm{~nm})$ is provided by Srivastava and Singh (1988). For detailed information, readers may refer Ono and Hirasawa (1992) and Ono (1993). Vertical profiles of the volume emission rates for $557.7 \mathrm{~nm}(\mathrm{Ol})$ and $630.0 \mathrm{~nm}(\mathrm{OI})$ are shown in Figure 4. For both spectra of precipitating electrons, the volume emission rate at $630.0 \mathrm{~nm}$ dominates that 

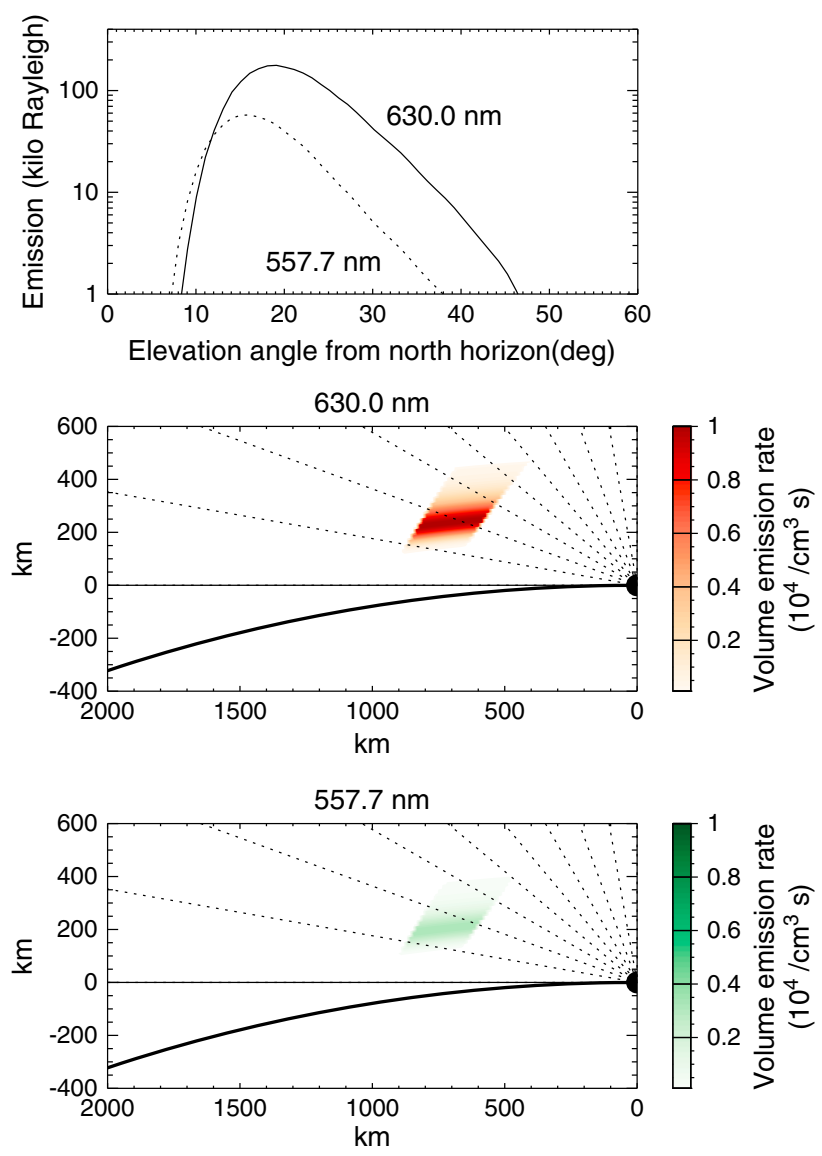

Figure 6. Same as Figure 5 except for Spectrum B. Electron precipitation is restricted in the region between $32^{\circ}$ and $34^{\circ}$ invariant latitudes. at $557.7 \mathrm{~nm}$ at high altitudes. The volume emission rate for $557.7 \mathrm{~nm}$ is significantly large at low altitudes for Spectrum A.

We used the dipole magnetic field to take into consideration of the magnetic inclination. Two-dimensional distribution of the volume emission rate was calculated for given precipitating electrons. An observer (a witness) is assumed to be located at $25^{\circ} \mathrm{MLAT}$, which approximately corresponds to Kyoto, Nagoya, and Toyoda in Japan. The column emission rate was calculated by performing a line-of-sight integral of the volume emission rate from the point of the observer toward the magnetic north. Atmospheric extinction and atmospheric refraction were not taken into consideration in the calculation.

\section{Results}

Figure 5 summarizes the column and volume emission rates for precipitating electrons with Spectrum A. The electron precipitation is restricted in the region between $40^{\circ}$ and $42^{\circ}$ invariant latitudes (ILATs). Figure 5 (top) shows the column emission rates in the direction of the magnetic north as a function of elevation angle. The lower green border is hidden below the horizon. For example, at elevation angle of $5^{\circ}$, the column emission rate at $630.0 \mathrm{~nm} \mathrm{I(630.0)}$ is $94 \mathrm{kR}$, whereas that at $557.7 \mathrm{~nm} /(557.7)$ is $12 \mathrm{kR}$. The observer likely sees a reddish aurora as suggested by Shiokawa et al. (1997) as we mention human visual perception below. In the second and third panels, volume emission rates at $630.0 \mathrm{~nm}$ and $557.7 \mathrm{~nm}$ are shown, respectively. Due to relatively low inclination angle of the magnetic field line, the auroral slab inclines toward the observer. The inclined magnetic field results in extension of the auroral display toward high altitude for the observer located at lower magnetic latitude. However, it seems difficult to extend up beyond the polar star (elevation angle of $\sim 35^{\circ}$ ) as described in Toyoda. For precipitating electrons at $40^{\circ}$ ILAT, sufficient volume emission rate at altitude of $970 \mathrm{~km}$ is required to observe the aurora at the elevation angle of $35^{\circ}$. Auroral emission at altitude of $970 \mathrm{~km}$ is negligibly small. The auroral display would extend up beyond the polar star if the electron precipitation occurred at low latitudes. In this case, the lower green border is no longer hidden. The auroral display with bright, lower green border is expected to appear (not shown). This is probably inconsistent with the drawing shown in Figure 1.

Figure 6 is the same as Figure 5 except for precipitating electrons with Spectrum B. The electron precipitation is restricted in the region between $32^{\circ}$ and $34^{\circ}$ ILATs. I(630.0) is larger than $/(557.7)$ at the elevation angle greater than $12^{\circ}$. The elevation angle at which the brightness is one tenth $I_{\max }(630.0)$ is $\sim 35^{\circ}$. This is probably consistent with the description that the aurora extended up beyond the polar star in Toyoda, Japan $\left(\mathrm{N} 34^{\circ} 52^{\prime}, \mathrm{E} 137^{\circ} 49^{\prime}, 25.0^{\circ} \mathrm{MLAT}\right) . I_{\max }(630.0)$ is 3.1 times larger than $I_{\max }(557.7)$. The auroral display may still include a lower green border. At the lower green border (where $I(557.7)>I(630.0)$ ), $I(557.7)$ is about an order of magnitude less than $I_{\text {max }}(630.0)$. Thus, the lower green border may be inconspicuous in comparison with the lower green border caused by Spectrum $A$.

We present Figure 7 to estimate the visual consequence of the aurora. In Figure 7 (top), the elevation angle at which $I(630.0)=I(557.7)$ is shown by the solid line as a function of ILAT of the equatorward edge of the electron precipitation. The latitudinal thickness of the electron precipitation was fixed to be $2^{\circ}$. The dashed line indicates the elevation angle where $I(630.0)$ is a tenth of $I_{\max }(630.0)$. To explain the description that the aurora extended up beyond the polar star (elevation angle being $\geq \sim 35^{\circ}$ ) in Toyoda, the equatorward edge of the electron precipitation was probably located as low as $32^{\circ}$ MLAT. In Figure 7 (bottom), the ratio $I_{\max }(630.0)$ to $I_{\max }(557.7)$ is present. The ratio is greater than 3 regardless of the latitude of the equatorward edge of the electron precipitation. We have to point out that human visual perception of brightness depends on wavelength of light. The photopic luminosity function specified by CIE 1931 (CIE data of 1931 available at http://cvision.ucsd.edu and http://www.cvrl.org, 1978) states 

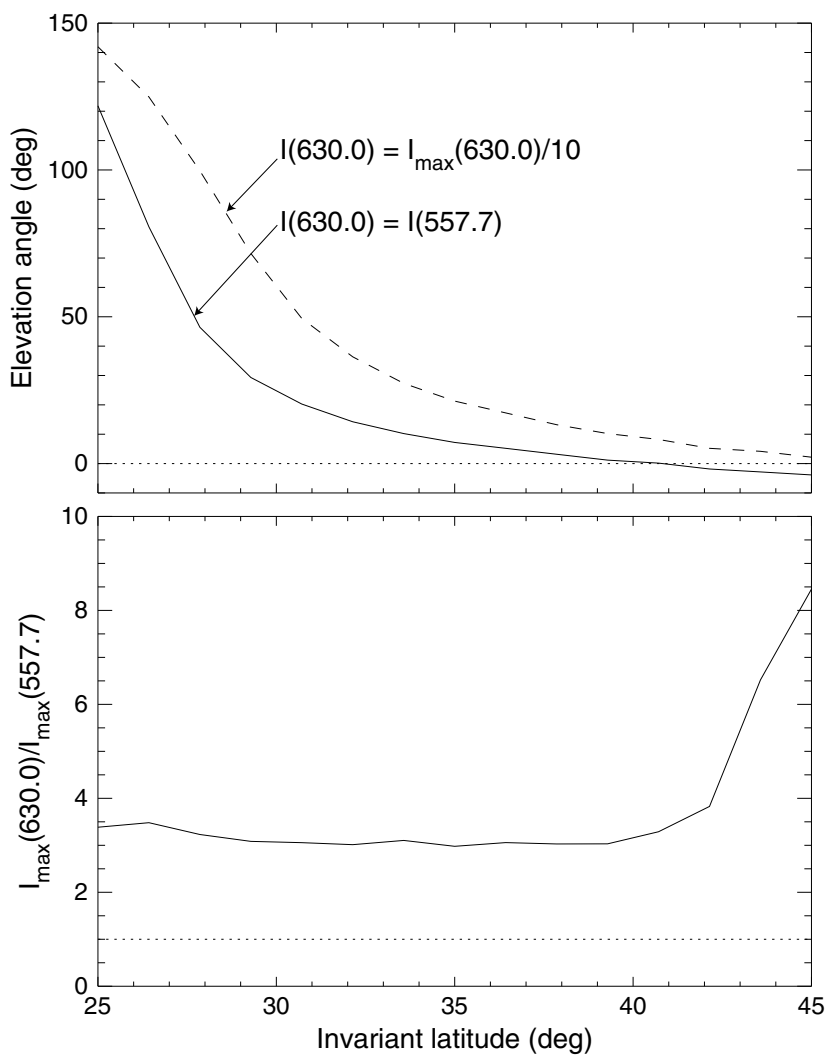

Figure 7. (top) The solid line indicates the elevation angle where $I(630.0)$ is equal to /(557.7) as a function of the invariant latitude of the equatorward boundary of the electron precipitation. The latitudinal thickness of the electron precipitation is assumed to be $2^{\circ}$. The dashed line indicates the elevation angle where $I(630.0)$ is a tenth of $I_{\max }(630.0)$, where $I_{\max }$ is the maximum column emission rate. (bottom) The ratio of the maximum column emission rate $I_{\max }(630.0) / I_{\max }(557.7)$ is shown. that the sensitivity ratio of $630.0 \mathrm{~nm}$ to that of $557.7 \mathrm{~nm}$ is $\sim 22 \%$. This probably means that the auroral display may include greenish yellow or greenish orange color because of a physiological blending of red and green colors (Chamberlain, 1961). This may explain the description "with golden color" described in Toyoda. We also note that the elevation angle at which $I(630.0)=I(557.7)$ does not immediately mean the elevation angle at which the red aurora starts to dominate the green one because of the human visual perception depending on wavelength.

We also tested the case in which the electron precipitation occurred in the region between $32^{\circ}$ and $42^{\circ}$ ILATs. The emission rates are shown in Figure 8 . The auroral display may extend from near the horizon, and the lower green border is almost absent. This may be consistent with the historical description and the drawing shown in Figure 1.

\section{Discussion}

Miyaoka et al. (1990) showed intensification of low-energy electrons $(<300 \mathrm{eV})$ associated with the red aurora observed at Moshiri on 21 October 1989. The flux of precipitating electrons is on the order of $10^{11} \mathrm{eV} / \mathrm{cm}^{2} \mathrm{~s} \mathrm{str}$, which is probably insufficient to explain the description regarding the bright aurora witnessed on 17 September 1770 . The calculated column emission rates at $630.0 \mathrm{~nm}$ is $177 \mathrm{kR}$ for Spectrum B (total flux of $5.7 \times 10^{12} \mathrm{eV} / \mathrm{cm}^{2} \mathrm{~s} \mathrm{str}$ ) when the electron precipitation occurs in the region between at $32^{\circ}$ and $34^{\circ}$ ILAT (Figure 6). The column emission rate increases to $378 \mathrm{kR}$ when the electron precipitation occurs in the region between at $32^{\circ}$ and $42^{\circ}$ ILAT (Figure 7). The column emission rate of $378 \mathrm{kR}$ at $630.0 \mathrm{~nm}$ is probably too low to reach the magnitude corresponding to IBC Class IV. Considering human visual perception of brightness, precipitating electron flux being an order of magnitude greater than that of Spectrum B is probably necessary to reach the magnitude equivalent to IBC Class IV. Of course, we cannot quantitatively argue the absolute brightness, electron flux, and latitudinal extend of the precipitation region because of absent of quantitative observation. In spite of the limitation, it is expected from the calculation that a combination of the high-intensity low-energy electrons (HILEEs) and equatorward displacement of electron precipitation region is required to explain the drawing and descriptions of the low-latitude aurora witnessed on 17 September 1770. From this sense, the extremely bright type $A$ aurora witnessed in East Asia in September 1770 is probably different from the low-latitude aurora that is caused by broadband electrons as reported by Shiokawa et al. $(1997,2005)$. The cause of the HILEEs is the key in the cause of the bright type $A$ aurora at low latitudes.

There are two types of possible mechanisms to generate the HILEEs at $32^{\circ}$ ILAT $(L=1.39)$. One type is the earthward displacement of plasma from the outer region by the enhanced magnetospheric convection. When the dawn-dusk convection electric field is intensified, charged particles originating in the outer region can penetrate deep inside the magnetosphere under the action of the $E \times B$ drift, grad- $B$ drift, and the curvature drift (Ejiri, 1978). A cross-polar cap potential is used to be a proxy of the magnetospheric convection. In quiet times, the cross-polar cap potential is $\sim 20 \mathrm{kV}$. The potential drop was observed to reach $257 \mathrm{kV}$ during the large storm of 31 March 2001 (Hairston, Hill, \& Heelis, 2003). The equatorward edge of the proton plasma sheet was observed to be $L \sim 1.5$ during the 20 November 2003 storm (Ebihara et al., 2005) when the maximum cross-polar cap potential was $224 \mathrm{kV}$ (Hairston, Drake, \& Skoug, 2005). It is expected that on 17 September 1770, the polar cap potential was comparable or larger than during the 31 March 2001 and 20 November 2003 storms. Let us consider motion of an electron with energy of $70 \mathrm{eV}$ (approximate peak energy of Spectrum B) and equatorial pitch angle of $40^{\circ}$ (near the loss cone angle). The electron is trapped on the field line at $L=1.39$ (32 ${ }^{\circ}$ ILAT). We assume the dipole magnetic field and conservation of first two adiabatic invariants. If the electron originated at 

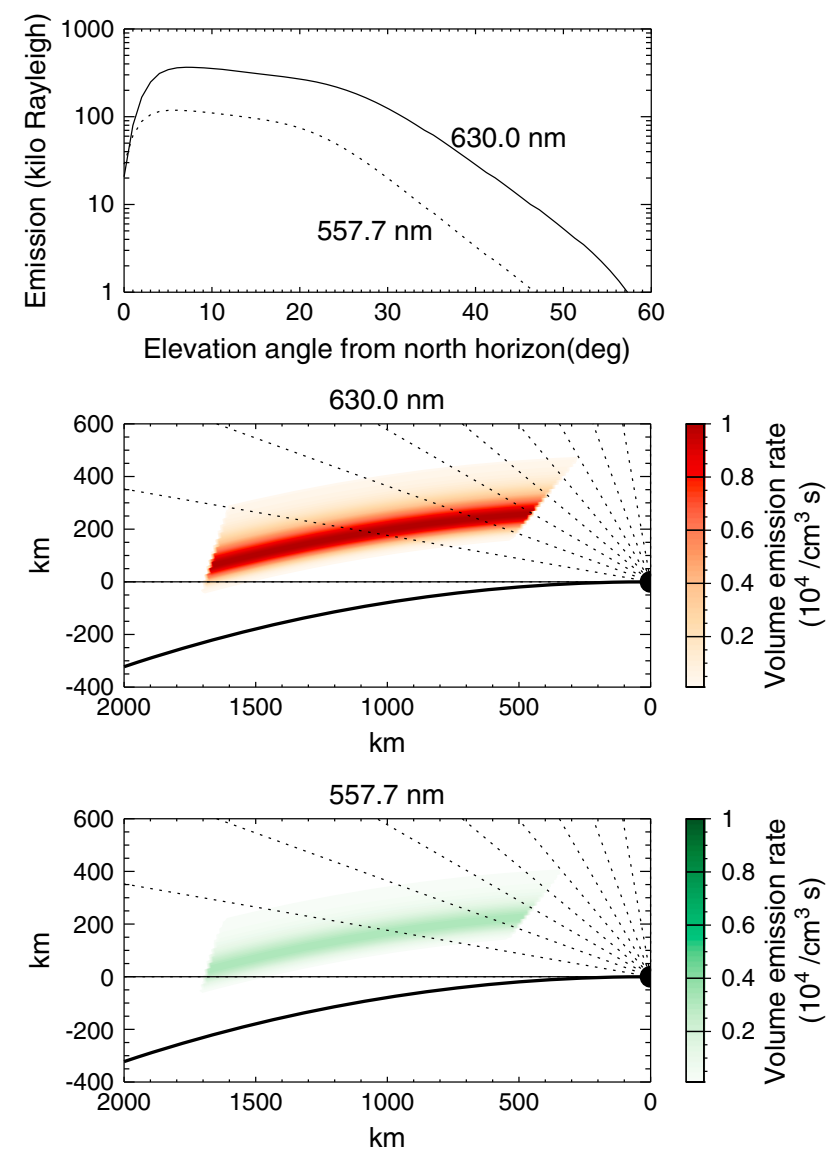

Figure 8. Same as Figure 6 except that the electrons precipitate in the region between $32^{\circ}$ and $42^{\circ}$ ILATs.
$L=6$, the kinetic energy would be $1.6 \mathrm{eV}$ at $L=6$ (Ejiri, 1978). This is much lower than typical temperature of the plasma sheet (Denton et al., 2005). A cold component of the plasma sheet (Ebihara, Kistler, \& Eliasson, 2008; Seki et al., 2003) or energetic component of the plasmasphere (e.g., Farrugia et al., 1989) would be plausible if the electrons were transported from the outer region. The electrons are probably scattered by interaction with waves or enlargement of the loss cone. The loss cone angle is $35.8^{\circ}$ at $32^{\circ}$ ILAT $(L=1.39)$ for the dipole magnetic field when the absorption takes place at $400 \mathrm{~km}$ altitude. Local generation of the HILEEs is also plausible. Local heating of plasmaspheric electrons probably generate the HILEEs due to Coulomb interaction between the cold plasmaspheric plasma and the hot plasma sheet plasma. This is similar to the mechanism for the SAR arcs (Kozyra et al., 1987; Rees \& Roble, 1975). Another one is interaction of cold electrons with inertia Alfvén waves, resulting in fieldaligned suprathermal electron bursts (e.g., Watt et al., 2005).

The auroral display would extend up to the elevation angle of $35^{\circ}$ if the equatorward boundary of the electron precipitation was located at $32^{\circ}$ ILAT, or less. The auroral display would extend from near the horizon if the poleward boundary of the electron precipitation was located at $42^{\circ}$ ILAT, or greater. In order to satisfy both the conditions, the electron precipitation would range, at least, from $32^{\circ}$ to $42^{\circ}$ ILATs for Spectrum B (HILEE). Of course, the latitudinal limits are subject to change, depending on the spectrum of precipitating electrons and sensitivity of the eyes.

A problem is the latitudinal width of the precipitation of the HILEE. As far as we surveyed, HILEEs with latitudinal width of $10^{\circ}$ have not been found. It is speculated that unusual processes that generated the HILEEs with latitudinal width of $10^{\circ}$ probably happened on 17 September 1770 . The possibility that the lower green border was hidden below the horizon may be ruled out. In order to hide the lower green border below the horizon, the equatorward boundary of the electron precipitation must be located at $37^{\circ}\left(42^{\circ}\right)$ ILAT, or greater for Spectrum A (Spectrum B). In this case, the auroral display cannot extend up beyond the elevation angle of $35^{\circ}$ for the observer located at $25^{\circ}$ MLAT.

\section{Conclusion}

The extremely bright aurora witnessed in East Asia on 17 September 1770 is probably realistic. The aurora was probably caused by precipitation of high-intensity low-energy electrons (HILEEs). The flux of HILEEs would be an order of magnitude greater than that observed in the 14 March 1989 magnetic storm to explain the description "as bright as a night with full moon." The equatorward edge of the electron precipitation was probably located at $32^{\circ}$ ILAT or lower to explain the description to explain the auroral display extending up beyond the elevation angle of $35^{\circ}$ (the polar star). The poleward edge of the electron precipitation is expected to be $42^{\circ}$ MLAT or higher to explain the auroral display extending from near the horizon in Nagoya, Japan. The HILEEs would result in an auroral display with a greenish yellow or greenish orange in the lower part of the auroral display because of a physiological blending of the red color and green color. Generation of the HILEEs is problematic. Earthward transport of cold electrons coming from the outer region or local heating of ambient electrons are expected to cause the HILEEs. Further studies are required to explain the generation of the HILEEs.

We can find records of extremely bright auroras in historical time other than the September 1770 event (e.g., Hayakawa et al., 2017). As we can trace back historical auroras for 2.5 millennia up to 567 before the Common Era (Hayakawa, Mitsuma, et al., 2016; Stephenson, Willis, \& Hallinan, 2004), this result and further surveys in historical records may help us to reconsider the brightness of auroras probably associated with magnetic storms in much longer time span. 
Acknowledgments

The two-stream electron transport code was originally developed by Takayuki Ono and was kindly provided by Yoshizumi Miyoshi. The DMSP particle detectors were designed by Dave Hardy of AFRL and data obtained from JHU/APL. The data from the DMSP satellite are available at the Web http:// sd-www.jhuapl.edu/Aurora/. We acknowledge support from RISH, Kyoto University, and the Kyoto University's Supporting Program the "UCHUGAKU" project. H. H. especially thanks $Y$. Sugimoto for his helpful comments on Seikai-M. We are also supported by JSPS KAKENHI JP15H03732 (PI: Y. Ebihara), JP16H03955 (PI: K. Shibata), JP15H05815 (PI: Y. Miyoshi), and JP17J06954 (PI: H. Hayakawa). The calculation data are available upon request. $\mathrm{H}$. H. especially thanks $Y$. Sugimoto for his helpful comments on Seikai-M. We also thank Matsusaka Municipal Library for Local History, the National Diet Library, and the Library of Research Institute for Humanity for allowing research and reproduction of their manuscript.

\section{References}

Chamberlain, J. W. (1961). Physics of the aurora and Airglow, pp. 124-125, https://doi.org/10.1029/SP041

CIE data of 1931 Retrieved from http://cvision.ucsd.edu and http://www.cvrl.org (1978). The CIE 1931 V( $\lambda$ ) data were modified by D. B. Judd and J. J. Vos in 1978. The Judd-Vos-modified eye sensitivity function is frequently referred to as VM $(\lambda)$; see J. J. Vos "Colorimetric and photometric properties of a 2-deg fundamental observer". Color Research and Application, 3, 125

Cliver, E. W., \& Dietrich, W. F. (2013). The 1859 space weather event revisited: Limits of extreme activity. Journal of Space Weather and Space Climate, 3, A31.

Cliver, E. W., \& Svalgaard, L. (2004). The 1859 solar-terrestrial disturbance And the current limits of extreme space weather activity. Solar Physics, 224, 407. https://doi.org/10.1007/s11207-005-4980-z

Denton, M. H., Thomsen, M. F., Korth, H., Lynch, S., Zhang, J. C., \& Liemohn, M. W. (2005). Bulk plasma properties at geosynchronous orbit. Journal of Geophysical Research, 110, A07223. https://doi.org/10.1029/2004JA010861

Ebihara, Y., Fok, M. C., Sazykin, S., Thomsen, M. F., Hairston, M. R., Evans, D. S., ... Ejiri, M. (2005). Ring current and the magnetosphereionosphere coupling during the superstorm of 20 November 2003. Journal of Geophysical Research, 110, A09S22. https://doi.org/10.1029/ 2004JA010924

Ebihara, Y., Kistler, L. M., \& Eliasson, L. (2008). Imaging cold ions in the plasma sheet from the Equator-S satellite. Geophysical Research Letters, 35, L15103. https://doi.org/10.1029/2008GL034357

Ejiri, M. (1978). Trajectory traces of charged particles in the magnetosphere. Journal of Geophysical Research, 83, 4798. https://doi.org/ 10.1029/JA083iA10p04798

Farrugia, C. J., Young, D. T., Geiss, J., \& Balsiger, H. (1989). The composition, temperature, and density structure of cold ions in the quiet terrestrial plasmasphere: GEOS 1 results. Journal of Geophysical Research, 94(A9), 11865. https://doi.org/10.1029/JA094iA09p11865

Gonzalez, W. D., Joselyn, J. A., Kamide, Y., Kroehl, H. W., Rostoker, G., Tsurutani, B. T., \& Vasyliunas, V. M. (1994). What is a geomagnetic storm? Journal of Geophysical Research, 99(A4), 5771-5792. https://doi.org/10.1029/93JA02867

Hairston, M. R., Drake, K. A., \& Skoug, R. (2005). Saturation of the ionospheric polar cap potential during the October-November 2003 superstorms. Journal of Geophysical Research, 110, A09S26. https://doi.org/10.1029/2004JA010864

Hairston, M. R., Hill, T. W., \& Heelis, R. A. (2003). Observed saturation of the ionospheric polar cap potential during the 31 March 2001 storm. Geophysical Research Letters, 30(6), 1325. https://doi.org/10.1029/2002GL015894

Hayakawa, H., Iwahashi, K., Tamazawa, H., Isobe, H., Kataoka, R., Ebihara, Y., ... Shibata, K. (2016). East Asian observations of low-latitude aurora during the Carrington magnetic storm. Publications of the Astronomical Society of Japan, 68, 99. https://doi.org/10.1093/pasj/ psw097

Hayakawa, H., Mitsuma, Y., Ebihara, Y., Kawamura, A. D., Miyahara, H., Tamazawa, H., \& Isobe, H. (2016). Earliest datable records of aurora-like phenomena in the astronomical diaries from Babylonia. Earth, Planets and Space, 68, 195. https://doi.org/10.1186/s40623-016-0571-5

Hayakawa, H., Tamazawa, T., Uchiyama, Y., Ebihara, Y., Miyahara, H., Kosaka, S., ... Isobe, H. (2017). Historical auroras in the 990s: Evidence of great magnetic storms. Solar Physics, 292(1), 12. https://doi.org/10.1007/s11207-016-1039-2

Hikosaka, T. (1958). On the great enhancement of the line [OI] 6300 in the aurora at Niigata on February 11, 1958. Report on lonospheric and Space Research Japan, 12, 469-471.

Hunten, D. M., Roach, F. E., \& Chamberlain, J. W. (1956). A photometric unit for the airglow and aurora. Journal of Atmospheric and Terrestrial Physics, 8(6), 345-346. https://doi.org/10.1016/0021-9169(56)90111-8

Jackson, A., Jonkers, A. R. T., \& Walker, M. (2000). Four centuries of geomagnetic secular variation from historical records. Philosophical transactions of the Royal Society. A, Mathematical, physical, and engineering sciences, 358, 957.

Kozyra, J. U., Shelley, E. G., Comfort, R. H., Brace, L. H., Cravens, T. E., \& Nagy, A. F. (1987). The role of ring current O ${ }^{+}$in the formation of stable auroral red arcs. Journal of Geophysical Research, 92(A7), 7487-7502. https://doi.org/10.1029/JA092iA07p07487

Lakhina, G. S., Alex, S., Tsurutani, B. T., \& Gonzalez, W. D. (2013). Supermagnetic Storms: Hazard to Society. In A. S. Sharma, et al. (Eds.), Extreme events and natural hazards: The complexity perspective (pp. 267-278). Washington, DC: American Geophysical Union. https://doi.org/ 10.1029/2011GM001073

Lakhina, G. S., \& Tsurutani, B. T. (2016). Geomagnetic storms: historical perspective to modern view. Geoscience Letters, 3, 5. https://doi.org/ 10.1186/s40562-016-0037-4

Loomis, E. (1860). The great auroral exhibition of August 28th to September 4th, 1859 (6th article). American Journal of Science, Second Series, 30(90), 339-361.

McEwen, D. J., \& Sivjee, G. G. (1972). Rocket measurements of electron influx during a major magnetic storm with type A aurora. Journal of Geophysical Research, 77(28), 5523-5529. https://doi.org/10.1029/JA077i028p05523

Miyaoka, H., Hirasawa, T., Yumoto, K., \& Tanaka, Y. (1990). Low latitude aurorae on October 21, 1989. I. Proceedings of the Japan Academy. Ser. B: Physical and Biological Sciences, 66(3), 47-51. https://doi.org/10.2183/pjab.66.47

Nakazawa, Y., Okada, T., \& Shiokawa, K. (2004). Understanding the "SEKKI" phenomena in Japanese historical literatures based on the modern science of low-latitude aurora. Earth, Planets and Space, 56, e41-e44. https://doi.org/10.1186/BF03353323

Noxon, J. F., \& Evans, J. V. (1976). Simultaneous optical and incoherent scatter observations of two low-latitude auroras. Planetary and Space Science, 24(5), 425-442. https://doi.org/10.1016/0032-0633(76)90086-6

Ono, T. (1993). Derivation of energy parameters of precipitating auroral electrons by using the intensity ratios of auroral emissions. Journal of Geomagnetism and Geoelectricity, 45(6), 455-472. https://doi.org/10.5636/jgg.45.455

Ono, T., \& Hirasawa, T. (1992). An apparent lifetime of auroral $630.0 \mathrm{~nm}$ (OI) emissions. Journal of Geomagnetism and Geoelectricity, 44(2), 91-108. https://doi.org/10.5636/jgg.44.91

Rassoul, H. K., Rohrbaugh, R. P., Tinsley, B. A., \& Slater, D. W. (1993). Spectrometric and photometric observations of low-latitude aurorae. Journal of Geophysical Research, 98(A5), 7695. https://doi.org/10.1029/92JA02269

Rees, M. H. (1961). On the excitation of suhvisual $01 \lambda \lambda 6300-6364$ arcs at middle latitudes. Planetary and Space Science, 8(3-4), 198-200. https://doi.org/10.1016/0032-0633(61)90276-8

Rees, M. H., \& Roble, R. G. (1975). Observations and theory of the formation of stable auroral red arcs. Reviews of Geophysics, 13(1), 201-242. https://doi.org/10.1029/RG013i001p00201

Rohrbaugh, R. P., Tinsley, B. A., Rassoul, H., Sahai, Y., Teixeira, N. R., Tull, R. G., ... Barker, E. S. (1983). Observations of optical emissions from precipitation of energetic neutral atoms and ions from the ring current. Journal of Geophysical Research, 88(A8), 6317-6330. https://doi.org/10.1029/JA088iA08p06317

Saito, B., Kiyama, Y., \& Takahasi, T. (1994). Spectral characteristics of low-latitude auroras observed from Japan on February 11,1958 and on May 10, 1992. Journal of Geomagnetism and Geoelectricity, 46(3), 253-262. https://doi.org/10.5636/jgg.46.253 
Seki, K., Hirahara, M., Hoshino, M., Terasawa, T., Elphic, R. C., Saito, Y., ... Matsumoto, H. (2003). Cold ions in the hot plasma sheet of Earth's magnetotail. Nature, 422(6932), 589-592. https://doi.org/10.1038/nature01502

Shiokawa, K., Otsuka, Y., Ogawa, T., Kawamura, T., Yamamoto, M., Fukao, S., ... Yumoto, K. (2003). Thermospheric wind during a storm-time large-scale traveling ionospheric disturbance. Journal of Geophysical Research, 108(A12), 1423. https://doi.org/10.1029/2003JA010001

Shiokawa, K., Meng, C.-I., Reeves, G. D., Rich, F. J., \& Yumoto, K. (1997). A multievent study of broadband electrons observed by the DMSP satellites and their relation to red aurora observed at midlatitude stations. Journal of Geophysical Research, 102(A7), 14237-14253. https://doi.org/10.1029/97JA00741

Shiokawa, K., Ogawa, T., \& Kamide, Y. (2005). Low-latitude auroras observed in Japan: 1999-2004. Journal of Geophysical Research, 110 A05202. https://doi.org/10.1029/2004JA010706

Srivastava, V., \& Singh, V. (1988). Model calculations of O('S) and O('D) emissions under proton bombardment. Journal of Geophysical Research, 93(A6), 5855-5869. https://doi.org/10.1029/JA093iA06p05855

Stephenson, F. R., Willis, D. M., \& Hallinan, T. J. (2004). The earliest datable observation of the aurora borealis. Astronomy \& Geophysics, 45, 6.15-6.17. https://doi.org/10.1046/j.1468-4004.2003.45615.x

Tinsley, B. A., Rohrbaugh, R., Rassoul, H., Sahai, Y., Teixeira, N. R., \& Slater, D. (1986). Low-latitude aurorae and storm time current systems. Journal of Geophysical Research, 91(A10), 11,257-11,269. https://doi.org/10.1029/JA091iA10p11257

Tinsley, B. A., Rohrbaugh, R. P., Rassoul, H., Barker, E. S., Cochran, A. L., Cochran, W. D., ... Slater, D. (1984). Spectral characteristics of two types of low latitude aurorae. Geophysical Research Letters, 11(6), 572-575. https://doi.org/10.1029/GL011i006p00572

Tsurutani, B. T., Gonzalez, W. D., Lakhina, G. S., \& Alex, S. (2003). The extreme magnetic storm of 1-2 September 1859. Journal of Geophysical Research, 108(A7), 1268. https://doi.org/10.1029/2002JA009504

Vallance Jones, A. (1971). Auroral Spectroscopy. Space Science Reviews, 11(6), 776-826.

Watt, C. E. J., Rankin, R., Rae, I. J., \& Wright, D. M. (2005). Self-consistent electron acceleration due to inertial Alfvén wave pulses. Journal of Geophysical Research, 110, A1OSO1. https://doi.org/10.1029/2004JA010877

Willis, D. M., Stephenson, F. R., \& Singh, J. R. (1996). Auroral observations on AD 1770 September 16: The earliest known conjugate sightings. Quarterly Journal of the Royal Astronomical Society, 37, 733-742.

Yokoyama, N., Kamide, Y., \& Miyaoka, H. (1998). The size of the auroral belt during magnetic storms. Annales de Geophysique, $16(5), 566$. https://doi.org/10.1007/s005850050626 